\title{
Editorial
}

\section{In Memoriam: Max P. Pepper}

Journal of Public Health Policy (20I7) 38, I-2.

doi:IO.I057/s4 I 27 I-OI6-0054-8; published online, I7 November 20 I 6

Max P. Pepper, MD, MPH, died on 22 September 2016 at 86 years of age at Baystate Franklin Medical Center in Greenfield, MA.

Max was a member of the editorial board of JPHP, one of a group of members who participated from the founding of the Journal by Milton Terris almost 40 years ago. He participated in the efforts, after Dr. Terris' death, to transition the journal to a new era with new editors. He helped secure the agreement of Anthony Robbins and Phyllis Freeman to take over and redesign this respected authoritative journal.

Max was a psychiatrist, part of a group at Yale Medical School in the I960s. They published in Social Psychiatry - the interaction of social determinants on the psychiatric status of individual patients. He was concerned with medical education and the impact of admission criteria on the racial composition of the medical student body. The Yale group pioneered as well in community psychiatry, with the creation in I966 of the Connecticut Mental Health Center.

He left New Haven in 1969 to found the Department of Community Medicine at St. Louis University College of Medicine and remained its Chair for the next 20 years. An innovative curriculum in Community Medicine featured teams of first year medical students interacting with local communities in St. Louis to assess and improve community health.

In 1989, Max returned to New England with his wife Anita, a professor of epidemiology and a strong advocate for improving health care services to the poor. She died in 200I. He was enrolled in the Yale School of Public Health's Honor Role of Alumni.

During his last years, despite increasing health incapacities, he traveled frequently to the University of Cape Town, South Africa to be part of the diverse faculty and to teach community medicine. As a child and young adult he studied piano before settling on medicine. He is 
survived by his two children: Thomas, a professor at the University of Minnesota and Sara Pepper-Sullivan of Northampton, MA.

Peter Orris

Editorial Board Member

E-mail: porris@uic.edu 